Eric Delva MD, Nicolas Sadoul MD,

Michel Chandon MD, Christine Boucherez MD, André Lienhart MD

\title{
Air embolism during liver resection: an unusual mechanism of entry from a peristaltic pump
}

A case of venous air embolism occurring during liver resection is reported. Diagnosis was made early from the continuous recording of pulmonary artery pressure. The aetiology was neither surgical nor an obvious disconnection of a venous line. It was caused by a blockage of the blood filter, resulting in subambient pressure between the filter and a peristaltic pump, leading to aspiration of numerous small air bubbles. The clinical course after replacement of the defective material was uneventful, except for transient postoperative pulmonary oedema.

Venous air embolism is a serious complication which can occur during liver surgery. ${ }^{1,2}$ The following case report describes how air embolism was recognized early because of continuous recording of pulmonary arterial pressure (PAP). The unusual aetiology, entry through a transfusion line, without obvious disconnection, was not however discovered until later.

\section{Case report}

A 38-year-old female was admitted for surgical resection of a liver angioma. The patient was classified as ASA physical status I.

\section{Key words}

COMPLICATIONS: air embolism; MONITORING: pulmonary arterial pressure; BLOOD TRANSFUSION: complications.

From the Department of Anaesthesia, Hôpital SaintAntoinc, Paris, France.

Address correspondence to: Dr. Eric Delva, Deparement d'Anesthésie-Réanimation, Hôpital Saint-Antoine, 184, Faubourg Saint-Antoine 75571 Paris Cedex 12.
Anaesthesia was induced with thiopentone and pancuronium and maintained with fentanyl, pancuronium and nitrous oxide $\left(\mathrm{N}_{2} \mathrm{O}\right), 60$ per cent in oxygen. Two venous catheters (16 and 18 gauge) were placed in the forearm and a central catheter was inserted through the left internal jugular vein. Arterial blood pressure and pulmonary artery pressure (PAP) ( 7 F Swan Ganz catheter) were continuously monitored. At laparotomy a vascularized mass was palpated in the caudate lobe of the liver, to the left of the inferior vena cava. During the resection of the caudate lobe a hepatic vein was accidently damaged, causing massive haemorrhage. Blood transfusion was started immediately through a peripheral catheter, via a peristaltic pump (Figure 1), at a rate of 100 to $150 \mathrm{ml} \cdot \mathrm{min}^{-1}$. In spite of the blood transfusion, heart rate increased and blood pressure fell. Moreover, during the rapid transfusion PAP and pulmonary capillary wedge pressure (PCWP) increased simultaneously from $20 / 10$ to $34 / 22 \mathrm{mmHg}$ and from 5 to $18 \mathrm{mmHg}$ respectively (Figure 2). Suddenly PAP rose sharply to $61 / 28 \mathrm{mmHg}$ while the PCWP decreased to $8 \mathrm{mmHg}$, with a diastolic PAP-PCWP gradient of $20 \mathrm{mmHg}$. The electrocardiogram showed no abnormality. Venous air embolism was suspected. All venous lines, stopcocks and connections were checked but no air leak was found, and no air entry had been noticed by the surgeon when repairing the hepatic vein. $\mathrm{N}_{2} \mathrm{O}$ was promptly discontinued and the rate of the blood transfusion was reduced (Figure 2). During preparations to aspirate blood and air from the central venous and pulmonary artery ports of the Swan Ganz catheter, the PAP returned to normal and the diastolic gradient decreased (Figure 2). The initial rate of the blood transfusion was resumed, leading once again to an 


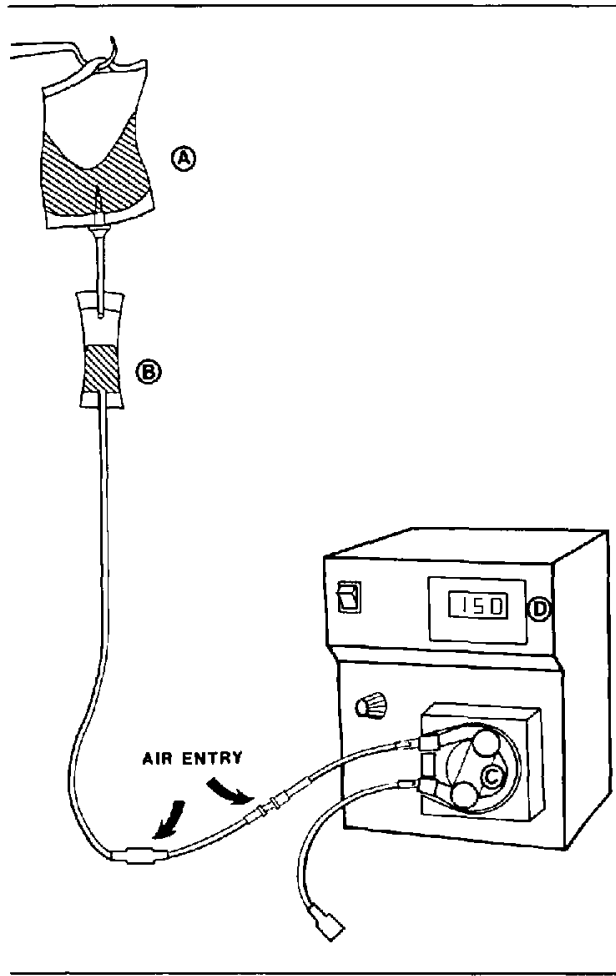

FIGURE 1 Peristaltic infusion pump. (A) packed red cells, (B) standard infusion line with filter $(170 \mu)$, (C) silicone tubing ( $5 \mathrm{ml}$ per rotation), (D) flow rate $(0-500 \mathrm{~mL}$ per minute).

increase in both PAP and the diastolic PAP-PCWP gradient (from 7 to $17 \mathrm{mmHg}$ ); there was no change in blood pressure or PCWP.

At this point a discrepancy between the setting on the peristaltic pump and the rate of blood flow in the filter was noticed. The transfusion line was reexamined carefully and numerous small air bubbles were discovered in it. The blood filter and transfusion line were replaced and the transfusion resumed (Figure 2). Within a few minutes the PAP and the diastolic gradient returned to normal. In 15 minutes the patient had received five units of packed red cells and three units of fresh frozen plasma through the peristaltic pump, for a total estimated blood loss of three liters.

Reintroduction of the $\mathrm{N}_{2} \mathrm{O}$ twenty minutes later did not cause any change in PAP and the surgical procedure was resumed without further incident. In the recovery room, the patient quickly regained consciousness and was extubated. A chest $x$-ray revealed pulmonary interstitial oedema with hilar clouding and bilateral Kerley's B lines, without any accompanying clinical signs. All evidence of pulmonary oedema disappeared within six hours. The patient made an uneventful recovery and was discharged six days following surgery.

\section{Discussion}

Massive haemorrhage and venous air embolism are potentially dangerous complications of major liver resection. ${ }^{1,2}$ To minimize the risk of air embolism surgical teams use different methods of hepatic vascular exclusion during hepatectomy. ${ }^{3,4}$ These risks and the possibility of vascular occlusion have led us to routinely use a Swan Ganz catheter for PAP monitoring during liver resection. ${ }^{4}$ An increase in PAP is indeed one of the earliest signs of air embolism and the degree of pulmonary hypertension has been shown to be proportional to its severity. ${ }^{5-7}$

During the first minutes of rapid blood transfusion, PAP and PCWP increased simultaneously, without any improvement in systemic blood pressure. These phenomena are often observed during rapid blood transfusion and probably result from transient depression of the myocardium by the citrate in the blood. ${ }^{8,9}$ Subsequently, PAP continued to increase as PCWP returned to normal, with a diastolic gradient of $20 \mathrm{mmHg}$. Venous air embolism was immediately suspected, but it took some time to discover the mechanism of air entry: not directly through the damaged vein but by a blockage of the blood filter, resulting in subambient pressure in the transfusion line controlled by the peristaltic pump, leading to aspiration of air.

The experimental model of this accident is clearly a continuous intravenous infusion of air, ${ }^{10,11}$ rather than a large single injection leading to an air lock in the heart. The increase in pulmonary arterial resistance explains the absence of an increase in PCWP which is observed only in large air emboli when the tip of the Swan Ganz catheter is in a branch of the occluded artery; the level of pulmonary arterial hypertension is proportional to the speed of the gas infusion and a dramatic fall in systemic arterial pressure is a late sign related to the right ventricular failure ${ }^{10.11}$ By contrast, when the air infusion is slow, pulmonary arterial hypertension may be associated with an increased 


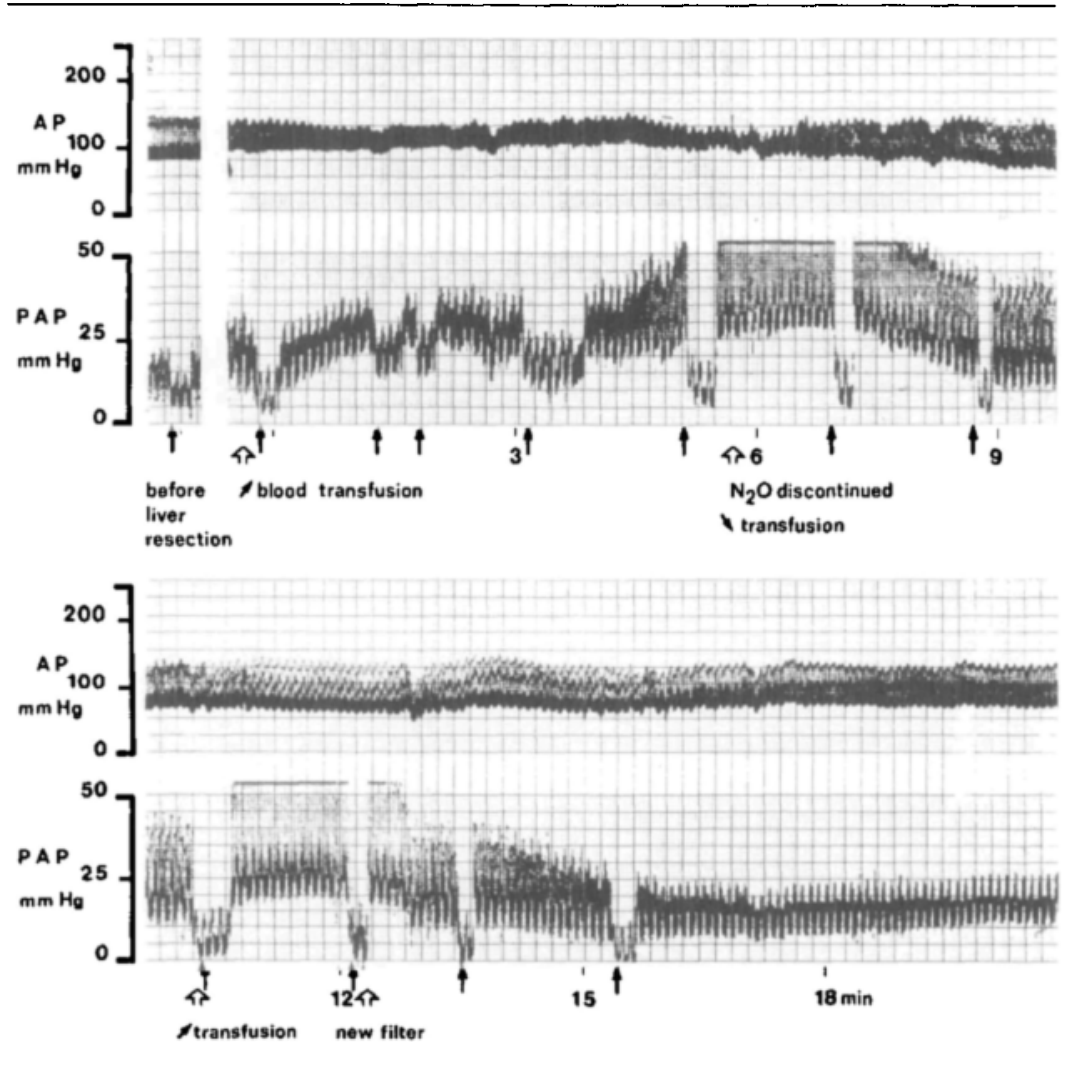

FIGURE 2 Record of arterial (AP), pulmonary arterial (PAP) and pulmonary capillary wedge pressures ( $\uparrow$ ) during air embolism. Events as indicated on figure.

cardiac output: ${ }^{11}$ these changes could explain the increase in systolic arterial pressure and the decrease in diastolic arterial pressure (Figure 2: $7 \mathrm{~min}$ ), although another explanation could be the beneficial effect on the right ventricular performance by the discontinuation of nitrous oxide.

Although the episodes of air embolism and pulmonary arterial hypertension were brief and were not associated with cardiovascular failure, the chest $x$-ray in the recovery room revealed interstitial pulmonary oedema. This phenomenon has been previously described during multiple ${ }^{12}$ or large ${ }^{13}$ air emboli and is mainly attributed to increased microvascular permeability, ${ }^{13}$ as PCWP was not increased when measured. ${ }^{7}$

This case report reemphasizes: (1) the risk of venous air embolism during the use of peristaltic infusion pumps at high flow rates, even without an obvious disconnection, and therefore illustrates the usefulness of equipping these pumps with photoelectric cells; (2) the efficacy of PAP monitoring which allows such an event to be identified during major surgery.

\section{References}

1 Iwatsuki S, Geis WP. Hepatic complications. Surg Clin North Am 1977; 57: 1335-56.

2 Strunin $L$, Davies $J M$. The liver and anaesthesia. Can Anaesth Soc J 1983; 30: 208-17.

3 Heaney JP, Stanton WK, Halbert DS, Seidel J, Vice T. An improved technic for vascular isolation of the liver. Ann Surg 1966; 163: 238-41.

4 Delva E, Barberousse JP, Nordlinger $B$ et al. 
Hemodynamic and biochemical monitoring during major liver resection with use of hepatic vascular exclusion. Surgery 1984; 95: 309-18.

5 Munson ES, Paul WL, Pery JC, De Padua CB, Rhoton $A L$. Early detection of venous air embolism using a Swan Ganz catheter. Anesthesiology, 1975; 42: $223-4$

6 Marshall WK, Bedford RF. Use of a pulmonaryartery catheter for detection and treatment of venous air embolism. Anesthesiology, 1980; 52; 131-4.

7 Lienhart A, Bagnat E, Guggiari $M$. Intraoperative air embolism. In: "Anaesthesia and postoperative care in uncommon diseases." Excerpta Medica Publish Amsterdam 1980, 101-18.

8 Bunker JP, Bendixen HH, Murphy A.J. Hemodynamic effects of intravenously administered sodium citrate. N Engl J Med, 1962; 266: 372-7.

9 Cooper N, Brazier JR, Hottenrott C, Mulder DG, Maloney $J V$, Buckberg GD. Myocardial depression following citrated blood transfusion. Arch Surg 1973; 107: 756-63.

10 Verstappen FTJ, Bernards JA, Kreuzer F. Effects of pulmonary gas embolism on circulation and respiration in the dog. I. Effects on circulation. Pfluegers Arch 1977; 368: 89-96.

11 Adornato DC, Gildenberg PL. Ferrario CM, Smart J, Frost EAM. Pathophysiology of intravenous air embolism in dogs. Anesthesiology 1978; 49: $120-7$.

12 Perschau RA, Munson ES, Chapin JC. Pulmonary interstitial edema after multiple venous air emboli. Anesthesiology 1976; 45: 364-8

13 Clark MC, Flick MR. Permeability pulmonary edema caused by venous air cmbolism. Am Rev Respir Dis 1984; 129: 633-5.
Résumé

Un cas d'embolie gazeuse d'origine veineuse survenu lors d'une hépatectomie est rapporté. Le diagnostic précoce a été permis par l'enregistrement continu de la pression artérielle pulmonaire. L'origine de l'embole n'êtait ni chirurgicale ni une déconnexion évidente sur une voie veineuse, mais une obstruction du filtre à sang provoquant une pression négative entre ce filtre et la pompe péristalique, à l'origine de l'aspiration de nombreuses petites bulles d'air. L'évolution clinique une fois le matériel défectueux remplacé fut favorable. 